\title{
An analysis of the interactions between the spine, pelvis, and lower limbs in asymptomatic adults with limited pelvic compensation
}

\author{
Shibin Shu ${ }^{1,2 \#}$, Zongshan $\mathrm{Hu}^{1,2,3 \#}$, Hongda Bao ${ }^{1,2}$, Jian Shi ${ }^{4}$, Anning $\mathrm{Hu}^{4}$, Michael Grelat ${ }^{5}$, Zhen Liu ${ }^{1,2}$, \\ Xu Sun ${ }^{1,2}$, Bangping Qian ${ }^{1,2}$, Jack C. Y. Cheng ${ }^{2,3}$, Tsz-Ping Lam ${ }^{2,3}$, Winnie W. C. Chu ${ }^{6}$, Yong Qiu ${ }^{1,2}$, \\ Zezhang Zhu ${ }^{1,2}$
}

${ }^{1}$ Department of Spine Surgery, Nanjing Drum Tower Hospital, Medical School of Nanjing University, Nanjing 210008, China; ${ }^{2}$ Joint Scoliosis Research Center of the Chinese University of Hong Kong and Nanjing University, Nanjing 210008, China; ${ }^{3}$ Department of Orthopaedics and Traumatology, Faculty of Medicine, The Chinese University of Hong Kong, Prince of Wales Hospital, Hong Kong, China; ${ }^{4}$ Department of Radiology, Nanjing Drum Tower Hospital, Medical School of Nanjing University, Nanjing 210008, China; ${ }^{5}$ Department of Neurosurgery, Dijon University Hospital, Dijon, France; ${ }^{6}$ Department of Imaging and Interventional Radiology, Prince of Wales Hospital, The Chinese University of Hong Kong, Prince of Wales Hospital, Hong Kong, China

\#These authors contributed equally to this work.

Correspondence to: Zezhang Zhu, MD. Spine Surgery, Drum Tower Hospital, Medical School of Nanjing University, Zhongshan Road 321, Nanjing 210008, China. Email: zhuzezhang@126.com.

Background: The interactions between the spine, pelvis, and lower limbs are dynamic based on the "cone of economy" concept; thus, different global radiographic parameters could be regarded as reflections of different centers of gravity. We conducted this retrospective study to evaluate the offsets of different centers of gravity in asymptomatic populations and to investigate how the global sagittal alignment is supported.

Methods: The following parameters were measured: cervical lordosis, thoracic kyphosis (TK), lumbar lordosis (LL), pelvic incidence (PI), pelvic tilt (PT), the ratio between PT and PI (PT/PI), sacral slope, PI minus LL (PI-LL), the sagittal vertical axis (SVA), cranial SVA to ankle center (Cr-A), CrSVA to the femoral head center $(\mathrm{Cr}-\mathrm{FH}), \mathrm{C} 2 \mathrm{SVA}$ to the femoral head center (C2-FH), pelvic translation (P. Shift), and knee angle (KA). Participants were divided into subgroups based on the PT/PI ratio. Mean values were compared using the $t$-test, and correlations were assessed using Pearson's coefficient.

Results: A total of 82 asymptomatic adults were enrolled. The average PT/PI in subgroup 1 was the smallest, showing that individuals in this group may have limited pelvic retroversion. No significant differences in $\mathrm{Cr}-\mathrm{FH}, \mathrm{Cr}-\mathrm{A}$, or $\mathrm{C} 2-\mathrm{FH}$ were found between subgroups (all $\mathrm{P}>0.1$ ), implying that global alignment was well supported in each group. Specifically, C2-FH showed minor changes between subgroups $(\mathrm{P}=0.998)$, showing that $\mathrm{C} 2-\mathrm{FH}$ may be a target for sagittal compensation. There were positive correlations between PT/PI and both P. Shift and SVA (r=0.930 and r=0.606, respectively). However, Cr-FH, Cr-A, and $\mathrm{C} 2-\mathrm{FH}$ were not significantly correlated with P. Shift or PT/PI (all P>0.05). Weak correlations existed between $\mathrm{Cr}-\mathrm{A}, \mathrm{Cr}-\mathrm{FH}$, and age (all $\mathrm{P}>0.2$ ).

Conclusions: This study revealed that the $\mathrm{Cr}-\mathrm{FH}$ and $\mathrm{C} 2-\mathrm{FH}$ offsets are stable across the population and could be maintained by regulating only the sagittal spinal curvature when pelvic compensation is limited. $\mathrm{Cr}-$ $\mathrm{FH}$ is not affected by age in the asymptomatic population. Thus, the stable $\mathrm{Cr}-\mathrm{FH}$ and $\mathrm{C} 2-\mathrm{FH}$ could provide references for surgeons during the surgical decision-making process in patients with adult spinal deformity with sagittal malalignment.

Keywords: Pelvic compensation; lower limbs; asymptomatic adults; full body 
Submitted Sep 20, 2019. Accepted for publication Apr 14, 2020.

doi: 10.21037/qims-19-785

View this article at: http://dx.doi.org/10.21037/qims-19-785

\section{Introduction}

The ability of the human body to maintain its center of gravity within the "cone of economy", while consuming minimal energy, is attributed to sagittal spinal balance $(1,2)$. Maintaining spinal balance relies on the complex interactions between the cervical, thoracic, and lumbar spines and the pelvis in conjunction with the lower limbs while minimizing muscle effort (3). Failure to maintain the cone of economy can lead to significant pain and disability $(4,5)$. When the sagittal profile of the spine changes, the pelvis adjusts and maintains the posture through interplay with the spine, controlling the lower back muscles, thus affecting energy expenditure (6). Therefore, detailed knowledge of the interaction between the spine and pelvis is essential to understanding sagittal harmony.

Individuals with sagittal global malalignment may progressively compensate with pelvic retroversion, lordosis of mobile spinal segments, and even flexion of the lower limbs to maintain an upright posture and horizontal gaze (7). This pelvic compensatory mechanism is an effective way of restoring the subject's balance and maintaining the body's center of gravity directly above the femoral heads (8). The pelvis takes the femoral head as the center and generates retroversion to compensate for the forward tilt of the trunk (9). Compensatory mechanisms of the pelvis can be quantified by pelvic tilt (PT), an angle proposed by DuvalBeaupère et al. (10), and subsequently correlated with the health-related quality-of-life (HRQOL) outcomes defined by Lafage et al. (5). The capacity of pelvic retroversion to participate in spinopelvic compensation can be affected by many factors, including pelvic anatomical features, hip-joint pathology, and soft tissue contractures (11). Individuals with low pelvic incidence (PI) have more anterior acetabular openings, with more natural hip extension, resulting in less capacity to adapt to sagittal malalignment (12). There is also a small subset of patients who have standard PI but a lack of pelvic compensation (13). The pathologic mechanisms responsible for limited pelvic retroversion should be investigated further.

The roles of the lower limbs in compensation, including hip extension, posterior pelvic translation (P. Shift), knee flexion, and ankle dorsiflexion utilized to maintain the gravity line (GL) over the ankle, have been confirmed in previous studies $(8,14)$. To better understand regional and global musculoskeletal mechanisms of compensation, global evaluation of sagittal alignment from head to foot is recommended. A prior study proposed the global sagittal axis (GSA) (15), a novel global angle sensitive to the spine, pelvis, and lower-limb compensatory mechanisms. More recently, Kim et al. introduced the cranial sagittal vertical axis (CrSVA) and demonstrated that CrSVA was better correlated to HRQOL than SVA in patients with adult spinal deformity (ASD) (16). Abstractly, the compensations of the spine, pelvis, and lower limbs are dynamic changes based on the "cone of economy" concept (17); thus, the global radiographic parameters should be reflective of the distribution of the centers of gravity in different parts of the body. For example, the CrSVA reflects the relative distribution between the centers of gravity of the head and trunk. Therefore, full-body global sagittal alignment can similarly be assessed by evaluating the distance between each gravity center.

The present study aims to evaluate the offsets of different centers of gravity in asymptomatic adults and to investigate how full-body global sagittal alignment is maintained in those with limited pelvic compensation.

\section{Methods}

\section{Subjects}

A cohort of 82 asymptomatic volunteers was prospectively recruited between January 1, 2016, and January 31, 2018. Volunteers were eligible to participate in the study based on the following inclusion criteria: (I) 18 years of age or older; (II) no history of spine or lower limb surgery; and (III) no pregnancy or malignancy. The exclusion criteria were as follows: (I) current, or a history of, hip-joint diseases; (II) a history of severe back pain; or (III) discrepancy or disease of the hip or lower limb. The institutional review board of each participating institution approved this study. All participating subjects signed written informed consent.

\section{Radiographic parameters}

All subjects underwent biplanar full-body, standing anteriorposterior (AP), and lateral stereo radiography imaging (EOS 

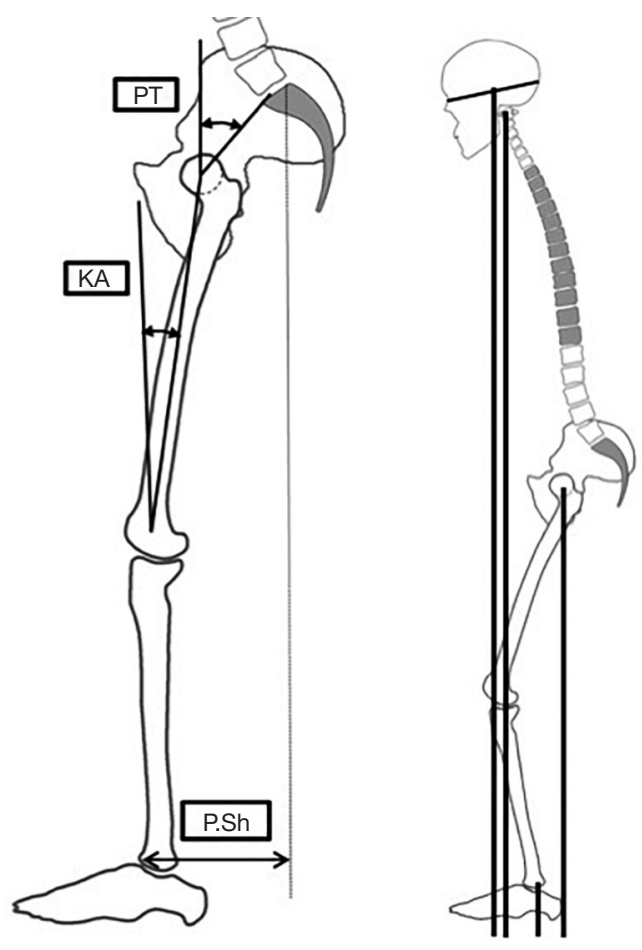

Figure 1 Radiographic parameters include the pelvic parameter of pelvic tilt (PT), the lower limb parameter of knee angle (KA), pelvic shift (P. Shift), and the horizontal offsets between CCOM and the center of $\mathrm{C} 2$, the center of the femoral head, and center of the ankle. PT, pelvic tilt; P. Shift, pelvic translation; CCOM, cranial center of mass.

imaging; Paris, France). The protocol included a weightbearing free-standing position of comfort with the arms flexed to avoid superimposition with the spine (18). AP and lateral images were simultaneously acquired and generated while the whole system was vertically translated, without vertical distortion (19).

All radiographic parameters were measured by a senior spine surgeon and a radiologist with experience in the diagnosis of skeletal diseases using Surgimap (Nemaris Inc., New York, NY, USA). The following radiographical parameters were assessed: (I) cervical lordosis (CL), defined as the angle between the lower endplate of $\mathrm{C} 2$ and the lower endplate of C7; (II) T4-T12 thoracic kyphosis (TK), defined as the angle between the upper endplate of T4 and the lower endplate of T12; (III) lumbar lordosis (LL), defined as the angle between the upper endplate of L1 and the upper endplate of S1; (IV) PI; (V) PT; (VI) sacral slope (SS) (20); (VII) SVA, defined as the offset between the vertical plumb line from the posterior edge of the base of the sacrum and the center of C7; (VIII) CrSVA to the ankle center (Cr-A); (IX) CrSVA to the femoral head center (Cr-FH); (X) C2SVA to the femoral head center (C2-FH); (XI) P. Shift; and (XII) knee angle (KA), defined as the angle between the mechanical axis of the femur and the mechanical axis of the tibia.

The Cr-A was defined as the horizontal offset between the cranial center of mass (CCOM) and center of the ankle (when the two ankles did not coincide, the midpoint of the line connecting the two centers was used). The Cr-A value was classified as negative or positive, meaning that the CCOM plumb line fell behind or in front of the ankle center, respectively (16). The $\mathrm{Cr}-\mathrm{FH}$ was defined as the horizontal offset between the CCOM and the center of the femoral head (when the two femoral heads did not coincide, the midpoint of the line connecting the two centers was taken). The Cr-FH value was classified as negative or positive, meaning that the CCOM plumb line fell behind or in front of the femoral head center, respectively. The $\mathrm{C} 2-\mathrm{FH}$ was defined as the horizontal offset between the center of $\mathrm{C} 2$ and the center of the femoral head (when the two femoral heads did not coincide, the midpoint of the line connecting the two centers was taken). The $\mathrm{C} 2-\mathrm{FH}$ value was classified as negative or positive, meaning that the $\mathrm{C} 2$ plumb line fell behind or in front of the femoral head center, respectively (Figure 1) (21). The P. Shift was defined as the horizontal offset between the $\mathrm{S} 1$ posteriorsuperior corner plumb line and the anterior cortex of the distal tibia. The P. Shift value was classified as negative or positive, meaning that the $\mathrm{S} 1$ posterior superior corner plumb line falls in front of or behind the anterior cortex of the distal tibia, respectively. The PT/PI was defined as the ratio between PT and PI and was calculated to compare the capacity of pelvic compensation between individuals (22).

\section{Statistical analysis}

Data were statistically analyzed using IBM SPSS Statistics version 23.0. Average values were reported as mean (SD). Summary statistics from the analyses of variance calculations were used to supply $95 \%$ confidence intervals for the error in measurements. Individuals were divided into four groups, from small to large, at intervals of the 25 th percentile of PT/PI. Subjects were also categorized based on their P. Shift into one of four groups as defined by the progressive value in the same increments. Each dependent variable was compared between the four groups by ANOVA. An independent-samples $t$-test was used to compare each 
Table 1 Comparison of demographics and radiographical parameters among four asymptomatic groups based on the degree of pelvic retroversion

\begin{tabular}{|c|c|c|c|c|c|}
\hline Variable & Group 1 & Group 2 & Group 3 & Group 4 & $\mathrm{P}$ \\
\hline Age (years) & $32.25 \pm 12.23$ & $38.30 \pm 21.81$ & $39.65 \pm 22.67$ & $62.91 \pm 19.43$ & $<0.001^{\star \star \star}$ \\
\hline PT/PI & $0.04 \pm 0.06$ & $0.20 \pm 0.03$ & $0.28 \pm 0.02$ & $0.40 \pm 0.07$ & $<0.001^{\star \star \star}$ \\
\hline $\mathrm{PT}\left({ }^{\circ}\right)$ & $1.63 \pm 2.78$ & $9.74 \pm 2.99$ & $11.63 \pm 2.95$ & $21.74 \pm 7.25$ & $<0.001^{\star \star \star}$ \\
\hline SS $\left(^{\circ}\right)$ & $39.98 \pm 7.57$ & $37.87 \pm 9.06$ & $29.96 \pm 6.24$ & $32.80 \pm 7.84$ & $<0.001^{\star * *}$ \\
\hline $\mathrm{KA}\left({ }^{\circ}\right)$ & $-0.24 \pm 3.71$ & $-0.91 \pm 4.29$ & $-2.43 \pm 4.38$ & $2.84 \pm 6.58$ & $0.007^{\star \star}$ \\
\hline $\operatorname{LL}\left({ }^{\circ}\right)$ & $51.36 \pm 9.03$ & $51.29 \pm 11.32$ & $43.16 \pm 10.78$ & $47.90 \pm 13.11$ & 0.076 \\
\hline PI-LL $\left(^{\circ}\right)$ & $-9.74 \pm 8.06$ & $-3.68 \pm 4.84$ & $-1.59 \pm 6.56$ & $6.64 \pm 11.59$ & $<0.001^{\star \star \star}$ \\
\hline $\mathrm{CL}\left({ }^{\circ}\right)$ & $0.21 \pm 10.89$ & $0.84 \pm 17.62$ & $5.69 \pm 12.69$ & $15.59 \pm 12.95$ & $0.001^{* *}$ \\
\hline SVA (mm) & $-6.09 \pm 25.52$ & $6.46 \pm 35.87$ & $7.21 \pm 29.13$ & $26.71 \pm 31.71$ & $0.009^{\star \star}$ \\
\hline P. Shift (mm) & $-27.11 \pm 17.96$ & $-10.26 \pm 30.32$ & $-11.99 \pm 26.34$ & $12.36 \pm 35.49$ & $<0.001^{\star \star *}$ \\
\hline $\mathrm{Cr}-\mathrm{A}(\mathrm{mm})$ & $34.05 \pm 26.20$ & $37.00 \pm 23.63$ & $40.51 \pm 27.18$ & $23.94 \pm 30.08$ & 0.224 \\
\hline $\mathrm{C} 2-\mathrm{FH}(\mathrm{mm})$ & $-11.31 \pm 24.95$ & $-9.70 \pm 38.20$ & $-11.17 \pm 32.59$ & $-10.55 \pm 27.20$ & 0.998 \\
\hline $\mathrm{Cr}-\mathrm{FH}(\mathrm{mm})$ & $-8.34 \pm 22.72$ & $-3.76 \pm 33.23$ & $-9.99 \pm 33.66$ & $-14.48 \pm 22.26$ & 0.676 \\
\hline
\end{tabular}

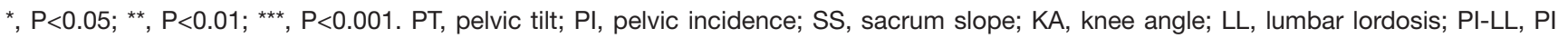
and LL mismatch; TK, thoracic kyphosis; CL, cervical lordosis; SVA, sagittal vertical axis; P. Shift, pelvic translation; Cr-A, cranial sagittal vertical axis-ankle; C2-FH, C2 sagittal vertical axis-femoral head; $\mathrm{Cr}-\mathrm{FH}$, cranial sagittal vertical axis-femoral head.

dependent variable between the subjects in each subgroup. Correlation tests were performed between radiographic parameters or with age. For all statistical analyses, the level of significance was set at $\mathrm{P}<0.05$.

\section{Results}

The age of the 82 subjects ( 40 men and 42 women) averaged $43.84 \pm 23.03$ years (range, $18-84$ years). The mean age of the men was $43.45 \pm 23.55$ years (range, $18-82$ years), which was comparable to the age of the women $(44.21 \pm 22.79$ years, $\mathrm{P}=0.882$ ).

Differences in demographic information and radiographic parameters among the four subgroups based on the PT/PI ratio are shown in Table 1. The average PT/ PI ratio in subgroup 1 was the smallest, showing that these individuals may have limited pelvic retroversion capacity. The spinal parameters (TK and CL) and KA in subgroup 1 adapted to the position of the pelvis and were smaller than those in the other groups (all $\mathrm{P}<0.05$ ). With the gradual increase of PT/PI value, the P. Shift, PT, PI-LL (16), CL, and TK had a corresponding gradual increase (all $\mathrm{P}<0.05$ ), whereas LL/TK had a gradual decrease.

Additionally, significant differences in KA were found among the four groups $(\mathrm{P}=0.007)$, while no significant statistical differences in LL were found between the groups $(\mathrm{P}=0.076)$. Comparisons of parameters between subgroups 1 and 2 showed no differences in PI between the two groups $(\mathrm{P}=0.069)$, and $\mathrm{SS}$ and LL both had no significant differences $(\mathrm{P}=0.392$ and 0.984 , respectively). Increased TK was found in subgroup 2, which may be because of pelvic retroversion. Comparing radiographic parameters between subgroups 1 and 3, PI was similar between the two groups $(\mathrm{P}=0.989)$, and $\mathrm{SS}$ was smaller in subgroup 3 due to increased PT. LL was smaller, and the spinal parameters (TK and CL) were higher in subgroup 3 than in subgroup 1 $(\mathrm{P}=0.023,0.033$, and 0.211 , respectively).

Regarding global alignment, SVA rose with the gradual 


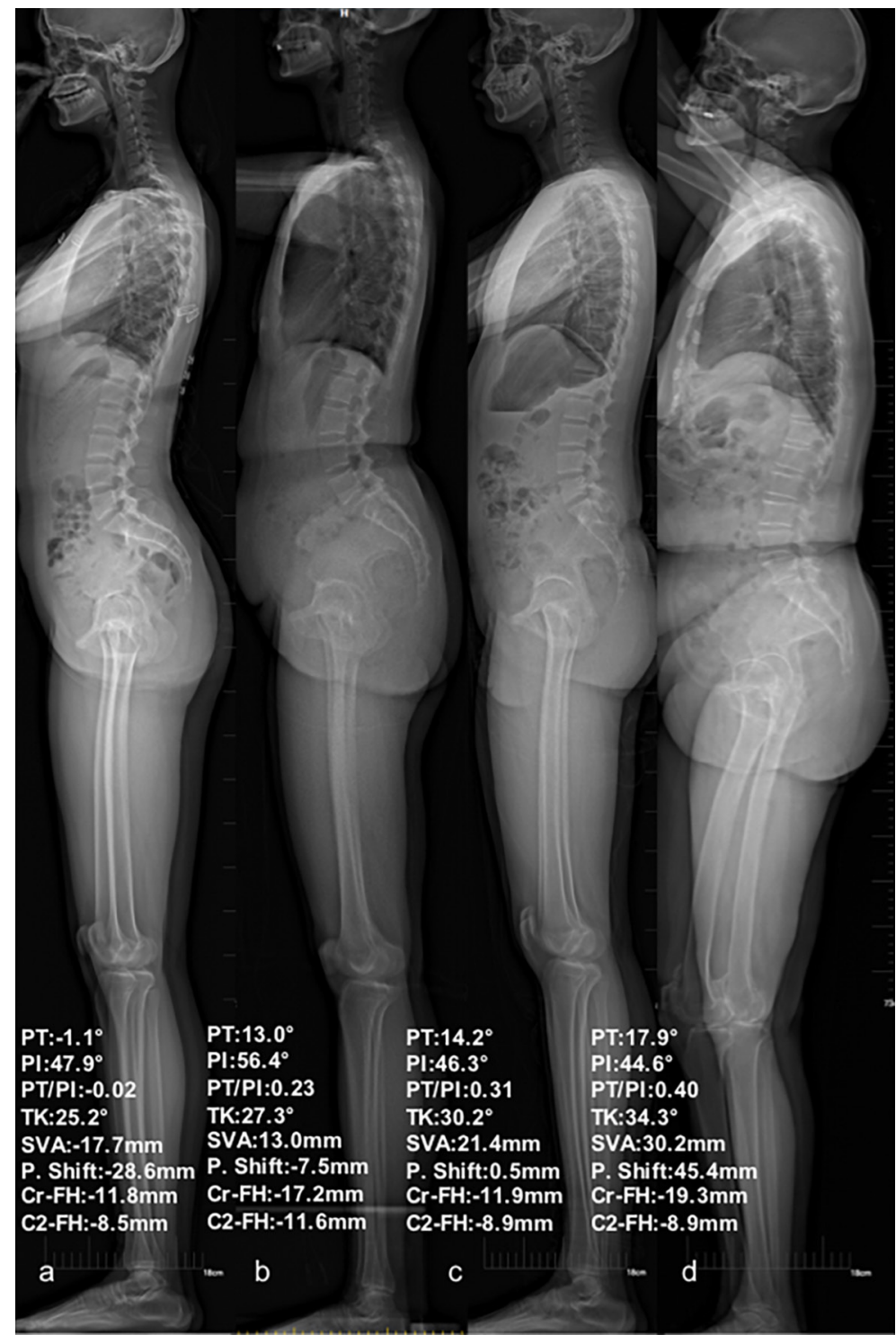

Figure 2 Four representatives of asymptomatic adults with different degrees of pelvic retroversion. As PT/PI increases, SVA and P. Shift increase, resulting in pelvic retroversion that manifests as a greater PT angle. However, the $\mathrm{Cr}-\mathrm{FH}$ and $\mathrm{C} 2-\mathrm{FH}$ offsets could be supported by regulating the sagittal spinal curvature, regardless of the pelvic retroversion. PT, pelvic tilt; PI, pelvic incidence; TK, thoracic kyphosis; SVA, sagittal vertical axis; P. Shift, pelvic translation; C2-FH, C2 sagittal vertical axis-femoral head; Cr-FH, cranial sagittal vertical axisfemoral head.

increase of the $\mathrm{PT} / \mathrm{PI}$ ratio $(\mathrm{P}=0.009)$. However, for anatomical offsets, no significant differences in $\mathrm{Cr}-\mathrm{FH}, \mathrm{Cr}-$ $\mathrm{A}$, or $\mathrm{C} 2-\mathrm{FH}$ were found among the four groups (all $\mathrm{P}>0.1$ ) (Figure 2). Specifically, C2-FH showed minor changes between the four subgroups $(\mathrm{P}=0.998)$, showing that $\mathrm{C} 2$ FH may be a target for sagittal compensation.

Pearson correlations between demographic or radiographical parameters are shown in Table 2. A strong positive correlation was found between P. Shift and PT/PI $(r=0.930, \mathrm{P}<0.001)$. P. Shift was also correlated with $\mathrm{PT}$ and SVA ( $r=0.524$ and 0.694, respectively). However, Cr-FH, $\mathrm{Cr}-\mathrm{A}$, and $\mathrm{C} 2-\mathrm{FH}$ were not significantly correlated with P. Shift or PT/PI (all $\mathrm{P}>0.05$ ). Furthermore, there was no correlation between KA and either P. Shift or PT/PI (both 
Table 2 Comparison of the correlations between sagittal and compensatory parameters

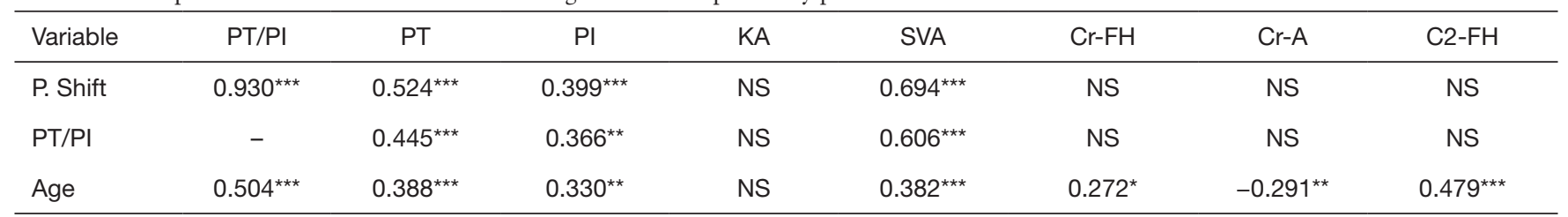

${ }^{*}, \mathrm{P}<0.05 ;{ }^{* \star}, \mathrm{P}<0.01 ;{ }^{* \star}, \mathrm{P}<0.001$. NS, no significance; P. Shift, pelvic translation; PT, pelvic tilt; PI, pelvic incidence; KA, knee angle; SVA, sagittal vertical axis; $\mathrm{Cr}-\mathrm{FH}$, cranial sagittal vertical axis-femoral head; Cr-A, cranial sagittal vertical axis-ankle; C2-FH, C2 sagittal vertical axis-femoral head.

$\mathrm{P}>0.05)$. Regarding the impact of age on alignment, there was a weak negative correlation between both $\mathrm{Cr}-\mathrm{A}$ and $\mathrm{Cr}-$ $\mathrm{FH}$ and age ( $\mathrm{r}=-0.291$ and 0.272 , respectively). There were moderate positive correlations between $\mathrm{C} 2-\mathrm{FH}$ and SVA and age ( $\mathrm{r}=0.479$ and 0.382 , respectively).

\section{Discussion}

Our results showed that asymptomatic individuals with limited pelvic compensation may compensate by reducing TK and CL while keeping Cr-FH, Cr-A, and C2-FH stable. Thus, the harmony of full-body alignment could be achieved by accommodating one parameter to another, supporting an upright and stable posture. Stable Cr-FH or C2-FH may also provide a reference for surgeons during the surgical decision-making process for patients with ASD with sagittal malalignment.

Sagittal compensatory mechanisms in patients with ASD have been thoroughly described by prior studies, proposing a cascading chain of compensation theory (23-25). This study is the first to report the normative values of full-body sagittal parameters in asymptomatic Chinese adults, as well as compensatory mechanisms in those with limited pelvic retroversion.

Pelvic compensation by retroverting the pelvis has been confirmed in previous studies $(5,17)$. Ferrero et al. described a subset of patients with ASD with low PT in which pelvic compensation was indicated to be limited, and found that those patients had increased disability and worse surgical outcomes (13). In our study, we also found a subgroup of asymptomatic individuals who had smaller PT/PI and smaller CL, TK, and P. Shift. Despite different degrees of pelvic retroversion, the sagittal spinal curvatures showed adaptations to the pelvic shapes, supporting the global sagittal alignment. Our results showed that LL was less related to PT/PI or PT but more related to SS; the spine adjusted TK for the adaptation of pelvic changes. TK and PT were recognized as compensatory mechanisms in patients with ASD, and the cascade was also reported (26). In asymptomatic individuals, the thoracic spine has adequate compensatory capacity (27); thus, sagittal alignment could be maintained in those with a small PT/PI (subgroup 1), although they may have a higher risk of sagittal malalignment once the capacity for thoracic compensation is exhausted due to the pelvic retroversion being limited.

The traditional metric of SVA can only assess the offset between $\mathrm{C} 7$ and the sacrum, ignoring the sagittal alignment of the whole body after cervical and lower-limb compensations. Recently, Kim et al. proposed CrSVA to assess sagittal global alignment, demonstrating that CrSVA is more predictive of clinical outcomes than SVA (16). In the present study, a similar philosophy was used, measuring the horizontal offset between anatomical landmarks, such as the center of the femoral head, center of the knee, and center of the ankle, and vertical line of the CCOM to reflect the global alignment of the body. The results revealed that the $\mathrm{Cr}-\mathrm{FH}$ and $\mathrm{C} 2-\mathrm{FH}$ were consistent among the four subgroups, categorized by the degree of pelvic compensation. Furthermore, $\mathrm{Cr}-\mathrm{FH}$ or $\mathrm{C} 2-\mathrm{FH}$ was not correlated with PT/PI or P. Shift, showing that Cr$\mathrm{FH}$ and $\mathrm{C} 2-\mathrm{FH}$ are not affected by pelvic compensation in asymptomatic individuals. Thus, stable Cr-FH and C2FH could be regarded as the harmonious result of multiple compensatory mechanisms.

Dubousset described the concept of the "cone of economy": a narrow range within which the body can remain balanced without external support and minimize energy use when maintaining an optimal upright posture (3). The less horizontal offset the body has between different regional centers of gravity, the less energy it consumes. Therefore, $\mathrm{Cr}-\mathrm{FH}$ and $\mathrm{C} 2-\mathrm{FH}$ may be a radiographic reflection of the balance status. In 2006, Schwab et al. described the GL in asymptomatic subjects in a force plate study (17). In their study, GL was found to be around the 
femoral heads: the offset between GL and the femoral heads was $5 \mathrm{~mm}$ in 21-40-year-old subjects, $6 \mathrm{~mm}$ in $41-60$-year-old subjects, and $13 \mathrm{~mm}$ in $>60$-year-old subjects. Therefore, the femoral heads may be regarded as the radiographic indicator of the GL, and the average values of $\mathrm{Cr}-\mathrm{FH}$ and $\mathrm{C} 2-\mathrm{FH}$ may provide crucial information for surgeons during surgical planning.

Analysis of the Pearson correlations revealed significant correlations between sagittal parameters (e.g., PT, PT/ PI, SVA, Cr-FH, and $\mathrm{C} 2-\mathrm{FH}$ ) and age. The comparative analysis between subgroups revealed larger sagittal curvatures and pelvic retroversion in aged individuals. Similar to our results, previous studies have described gradual increases in pelvic retroversion, TK, and SVA as being indicative of the aging of the spine $(28,29)$. To avoid overcorrection and the subsequent risk of proximal junctional kyphosis, Lafage et al. proposed an age-specific surgical target for alignment in patients with ASD (28). Bao et al. also noted different sagittal alignment patterns in asymptomatic US populations, reporting increased pelvic retroversion and lower limb involvement in the aged population (30). The results of our study provide additional evidence for these conclusions within an Asian population. Our results also revealed that $\mathrm{Cr}-\mathrm{FH}$ offsets were not significantly associated with age $(\mathrm{r}=0.272)$ in asymptomatic individuals, indicating that, even with the aging of the spine, the Cr-FH offset could be maintained by regulating other compensatory mechanisms. According to our results, we postulate that the $\mathrm{Cr}-\mathrm{FH}$ offset might be an alignment target in an asymptomatic population. Despite different degrees of pelvic retroversion and different ages, the body can regulate the spine and lower limbs to support a stable $\mathrm{Cr}-\mathrm{FH}$.

Despite the new information detailed above, this study has some limitations. The small sample size of the current analysis may diminish its power. Another limitation is the lack of validation of the assumed stable $\mathrm{Cr}-\mathrm{FH}$ offsets in patients with ASD. The link between $\mathrm{Cr}-\mathrm{FH}$ and HRQOL in patients with ASD should be evaluated in future studies.

\section{Conclusions}

This study revealed that the $\mathrm{Cr}-\mathrm{FH}$ and $\mathrm{C} 2-\mathrm{FH}$ are stable across the population and could be supported by regulating only the sagittal spinal curvature when pelvic compensation is limited. $\mathrm{Cr}-\mathrm{FH}$ is not affected by age in the asymptomatic population. Thus, the stable $\mathrm{Cr}-\mathrm{FH}$ and $\mathrm{C} 2-\mathrm{FH}$ could provide references for surgeons during the surgical decision-making process in patients with ASD with sagittal malalignment.

\section{Acknowledgments}

We want to thank Dr. Renaud Lafage for the schematic diagram.

Funding: This work received funding from the Youth Fund of Natural Science Foundation of Jiangsu Province (BK20180122) and the Special Funds for Health Science and Technology Development of Nanjing City (YKK18092).

\section{Footnote}

Conflicts of Interest: All authors have completed the ICMJE uniform disclosure form (available at http://dx.doi. org/10.21037/qims-19-785). The authors have no conflicts of interest to declare.

Ethical Statement: All procedures performed in studies involving human participants were following the ethical standards of the institutional and/or national research committee and with the 1964 Helsinki declaration and its later amendments or comparable ethical standards. Informed consent was obtained from all individual participants included in the study.

Open Access Statement: This is an Open Access article distributed in accordance with the Creative Commons Attribution-NonCommercial-NoDerivs 4.0 International License (CC BY-NC-ND 4.0), which permits the noncommercial replication and distribution of the article with the strict proviso that no changes or edits are made and the original work is properly cited (including links to both the formal publication through the relevant DOI and the license). See: https://creativecommons.org/licenses/by-nc-nd/4.0/.

\section{References}

1. Le Huec JC, Saddiki R, Franke J, Rigal J, Aunoble S. Equilibrium of the human body and the gravity line: the basics. Eur Spine J 2011;20 Suppl 5:558-63.

2. Dubousset J. Reflections of an orthopaedic surgeon on patient care and research into the condition of scoliosis. J Pediatr Orthop 2011;31:S1-8.

3. Dubousset J. Three-dimensional analysis of the scoliotic deformity. In: Weinstein SL, editor. The pediatric spine: principles and practice. New York: Raven Press Ltd.; 
1994:479-96.

4. Glassman SD, Bridwell K, Dimar JR, Horton W, Berven S, Schwab F. The impact of positive sagittal balance in adult spinal deformity. Spine (Phila Pa 1976) 2005;30:2024-9.

5. Lafage V, Schwab F, Patel A, Hawkinson N, Farcy JP. Pelvic tilt and truncal inclination: Two key radiographic parameters in the setting of adults with spinal deformity. Spine (Phila Pa 1976) 2009;34:E599-606.

6. Roussouly P, Pinheiro-Franco JL. Biomechanical analysis of the spino-pelvic organization and adaptation in pathology. Eur Spine J 2011;20 Suppl 5:609-18.

7. Yagi M, Ohne H, Konomi T, Fujiyoshi K, Kaneko S, Takemitsu M, Machida M, Yato Y, Asazuma T. Walking balance and compensatory gait mechanisms in surgically treated patients with adult spinal deformity. Spine J 2017;17:409-17.

8. Barrey C, Roussouly P, Le Huec JC, D'Acunzi G, Perrin G. Compensatory mechanisms contributing to keep the sagittal balance of the spine. Eur Spine J 2013;22 Suppl 6:S834-41.

9. Protopsaltis TS, Schwab FJ, Smith JS, Klineberg EO, Mundis GM, Hostin RA, Hart RA, Burton DC, Ames CP, Shaffrey CI, Bess RS, Errico TJ, Lafage V. The T1 Pelvic Angle (TPA), a Novel Radiographic Parameter of Sagittal Deformity, Correlates Strongly with Clinical Measures of Disability. Spine J 2013;13:S61.

10. Duval-Beaupère G, Schmidt C, Cosson P. A barycentremetric study of the sagittal shape of spine and pelvis: The conditions required for an economic standing position. Ann Biomed Eng 1992;20:451-62.

11. Protopsaltis T, Schwab F, Bronsard N, Smith JS, Klineberg E, Mundis G, Ryan DJ, Hostin R, Hart R, Burton D, Ames C, Shaffrey C, Bess S, Errico T, Lafage $\mathrm{V}$; International Spine Study Group. TheT1 pelvic angle, a novel radiographic measure of global sagittal deformity, accounts for both spinal inclination and pelvic tilt and correlates with health-related quality of life. J Bone Joint Surg Am 2014;96:1631-40.

12. Lazennec JY, Riwan A, Gravez F, Rousseau MA, Mora N, Gorin M, Lasne A, Catonne Y, Saillant G. Hip spine relationships: application to total hip arthroplasty. Hip Int 2007;17:S91-104.

13. Ferrero E, Vira S, Ames CP, Kebaish K, Obeid I, O'Brien MF, Gupta MC, Boachie-Adjei O, Smith JS, Mundis GM, Challier V, Protopsaltis TS, Schwab FJ, Lafage $\mathrm{V}$; International Spine Study Group. Analysis of an unexplored group of sagittal deformity patients: low pelvic tilt despite positive sagittal malalignment. Eur Spine J.
2016;25:3568-76.

14. Hasegawa K, Okamoto M, Hatsushikano S, Shimoda H, Ono M, Homma T, Watanabe K. Standing sagittal alignment of the whole axial skeleton with reference to the gravity line in humans. J Anat 2017;230:619-30.

15. Diebo BG, Oren JH, Challier V, Lafage R, Liu S, Vira S, Spiegel MA, Harris BY, Liabaud B, Henry JK, Errico TJ, Schwab FJ, Lafage L. Global Sagittal Axis (GSA): A step toward full body assessment of sagittal plane deformity in the human body. Journal of Neurosurgery: Spine 2016;25:494-9.

16. Kim YC, Lenke LG, Lee SJ, Gum JL, Wilartratsami S, Blanke KM. The cranial sagittal vertical axis (CrSVA) is a better radiographic measure to predict clinical outcomes in adult spinal deformity surgery than the C7 SVA: a monocentric study. Eur Spine J 2017;26:2167-75.

17. Schwab F, Lafage V, Boyce R, Skalli W, Farcy JP. Gravity line analysis in adult volunteers: Age-related correlation with spinal parameters, pelvic parameters, and foot position. Spine (Phila Pa 1976). 2006;31:E959-67.

18. Horton WC, Brown CW, Bridwell KH, Glassman SD, Suk SI, Cha CW. Is there an optimal patient stance for obtaining a lateral 36" radiograph?: A critical comparison of three techniques. Spine (Phila Pa 1976). 2005;30:427-33.

19. Ilharreborde B, Steffen JS, Nectoux E, Vital JM, Mazda K, Skalli W, Obeid I. Angle measurement reproducibility using EOS three-dimensional reconstructions in adolescent idiopathic scoliosis treated by posterior instrumentation. Spine (Phila Pa 1976) 2011;36:E1306-13.

20. Legaye J, Duval-Beaupère G, Hecquet J, Marty C. Pelvic incidence: A fundamental pelvic parameter for threedimensional regulation of spinal sagittal curves. Eur Spine J 1998;7:99-103.

21. Diebo BG, Varghese JJ, Lafage R, Schwab FJ, Lafage V. Sagittal alignment of the spine: What do you need to know? Clin Neurol Neurosurg 2015;139:295-301.

22. Mac-Thiong JM, Roussouly P, Berthonnaud E, Guigui P. Age- and sex-related variations in sagittal sacropelvic morphology and balance in asymptomatic adults. Eur Spine J 2011;20 Suppl 5:572-7.

23. Diebo BG, Ferrero E, Lafage R, Challier V, Liabaud B, Liu S, Vital JM, Errico TJ, Schwab FJ, Lafage V. Recruitment of compensatory mechanisms in sagittal spinal malalignment is age and regional deformity dependent: A full-standing axis analysis of key radiographical parameters. Spine (Phila Pa 1976) 2015;40:642-9.

24. Ferrero E, Liabaud B, Challier V, Lafage R, Diebo BG, Vira S, Liu S, Vital JM, Ilharreborde B, Protopsaltis TS, 
Errico TJ, Schwab FJ, Lafage V. Role of pelvic translation and lower-extremity compensation to maintain gravity line position in spinal deformity. J Neurosurg Spine 2016;24:436-46.

25. Le Huec JC, Hasegawa K. Normative values for the spine shape parameters using $3 \mathrm{D}$ standing analysis from a database of 268 asymptomatic Caucasian and Japanese subjects. Eur Spine J 2016;25:3630-7.

26. Takemoto M, Boissière L, Novoa F, Vital JM, Pellisé F, Pérez-Grueso FJ, Kleinstück F, Acaroglu ER, Alanay A, Obeid I, Obeid I; European Spine Study Group, ESSG. Sagittal malalignment has a significant association with postoperative leg pain in adult spinal deformity patients. Eur Spine J 2016;25:2442-51.

27. Wood KB, Garvey TA, Gundry C, Heithoff KB. Magnetic resonance imaging of the thoracic spine. Evaluation of asymptomatic individuals. J Bone Joint Surg Am

Cite this article as: Shu S, Hu Z, Bao H, Shi J, Hu A, Grelat M, Liu Z, Sun X, Qian B, Cheng JCY, Lam TP, Chu WWC, Qiu Y, Zhu $Z$. An analysis of the interactions between the spine, pelvis, and lower limbs in asymptomatic adults with limited pelvic compensation. Quant Imaging Med Surg 2020;10(5):999-1007. doi: 10.21037/qims-19-785
1995;77:1631-8.

28. Lafage R, Schwab F, Challier V, Henry JK, Gum J, Smith J, Hostin R, Shaffrey C, Kim HJ, Ames C, Scheer J, Klineberg E, Bess S, Burton D, Lafage V; International Spine Study Group. Defining Spino-Pelvic Alignment Thresholds. Spine (Phila Pa 1976) 2016;41:62-8.

29. Le Huec JC, Charosky S, Barrey C, Rigal J, Aunoble S. Sagittal imbalance cascade for simple degenerative spine and consequences: algorithm of decision for appropriate treatment. Eur Spine J 2011;20 Suppl 5:699-703.

30. Bao H, Lafage R, Liabaud B, Elysée J, Diebo BG, Poorman G, Jalai C, Passias P, Buckland A, Bess S, Errico T, Lenke LG, Gupta M, Kim HJ, Schwab F, Lafage V. Three types of sagittal alignment regarding compensation in asymptomatic adults: the contribution of the spine and lower limbs. Eur Spine J 2018;27:397-405. 